\title{
¿LA NATURALEZA PÚBLICA DEL DERECHO PRIVADO?*
}

\author{
The Public Nature of Private Law?
}

\author{
Claudio Michelon**
}

\begin{abstract}
Resumen
En este artículo el autor discute la perspectiva liberal de la esfera privada como un ámbito en el cual se justifica que los agentes actuén sin tomar en cuenta los intereses de los demás. El ámbito de lo privado no puede concebirse aisladamente del derecho público, el que a su vez debe ser concebido como la encarnación del interés mutuo de los miembros de la comunidad en el florecimiento de cada uno de ellos.
\end{abstract}

Palabras clave: derecho privado; esfera privada; reconocimiento

\begin{abstract}
:
In this paper the author challenges the liberal vision of the private sphere as a realm of in which agents are justified in acting without taking into consideration anyone else's interests. The private realm cannot be thought in isolation of public law, which should in turn be conceived as an embodiment of the mutual interest of the members of that group in the flourishing of one another.
\end{abstract}

Key words: private law; private sphere; recognition

\section{INTRODUCCIÓN}

Las teorías de lo público han tenido dificultades a menudo para ofrecer una explicación plausible del derecho privado. El derecho privado, entendido como el derecho del ámbito privado, a menudo es un mero complemento para el derecho y el ámbito públicos. Sin embargo, el derecho privado es, a fin de cuentas, derecho y, tal y como este artículo plantea, aquello lleva consigo un inescapable elemento público. Cualquier concepción del derecho que no sea puramente instrumentalista tendría que aceptar que el derecho representa más

* Publicado originalmente en inglés en Michelon, Claudio et al. (eds.), The Public in Law. Representations of the Political in Legal Discourse (Ashgate Publishing, 2012). Los editores agradecen la autorización de Ashgate Publishing para volver a publicar el artículo. Traducción al castellano de Joaquín Reyes.

** University of Edinburgh, Reino Unido (c.michelon@ed.ac.uk). 
que los intereses de alguna parte discreta del grupo social relevante (incluso de los de la 'mayoría' en ese grupo). Al hacerlo, tendría que aceptar que, a pesar de las apariencias en contrario, el derecho merece respeto como la encarnación del interés mutuo de los miembros de ese grupo en su realización recíproca. Esta concepción de la naturaleza política del derecho está destinada a ser polémica y lo que aquí se entiende por ella será aclarado (y matizado) más abajo. Este aspecto público del derecho privado parece en tensión con la idea de lo privado. De hecho, el ámbito privado, en su interpretación liberal canónica, se encuentra en oposición a la idea de 'lo público', en la medida en que se refiere a un espacio en el que uno está libre de la obligación de tomar en consideración las necesidades de los demás (menos aun su realización personal).

La frase 'derecho privado' puede entonces parecer un oxímoron. Sin embargo, esa impresión se funda en una incorrecta concepción sobre el objeto del derecho privado y de por qué es valioso preservarlo en una cierta forma (o eso es lo que este argumento defenderá). Lo privado puede entenderse, a través del derecho, como un espacio de interacción significativo. Eso no significa que el derecho privado enseñe a las personas a preocuparse unas de otras. Puede o no hacerlo en ciertos contextos, pero el argumento no depende de esa tesis empírica. El punto que este artículo intenta defender en lo que sigue es conceptual y tiene implicancias para las preguntas acerca de qué es lo que el derecho privado representa y qué forma debiera tener.

En el último siglo, la autocomprensión del derecho privado, la narrativa en la que encuentra su significado, ha sido una fuente constante de angustia existencial para los mejores privatistas. Uno de los objetivos centrales al defender la naturaleza pública del derecho privado en este artículo es esbozar una narrativa alternativa bajo la cual los importantes cambios sufridos por el derecho privado en el siglo veinte en la mayoría de los sistemas jurídicos occidentales puedan verse como el desarrollo de una idea, más que como la intrusión de ideas foráneas en el corpus central del 'verdadero' derecho privado.

Antes de plantear este punto es necesario, primero, desarrollar dos líneas argumentativas que serán luego de utilidad en la sección tercera. Primero, es necesario explicar qué se entiende por la afirmación de que el derecho está siempre fundado en la conexión entre los miembros de un grupo político particular (en la sección siguiente). Segundo, es necesario esbozar con mayor detalle la estructura conceptual que subyace a la comprensión liberal de la esfera privada, lo cual este artículo tratará de hacer en la sección que sigue a la próxima. 


\section{LA PRETENSIÓN DE CONECTIVIDAD DEL DERECHO}

Esta discusión comenzará con una explicación del sentido en que el derecho está ligado con una concepción anti individualista de lo político. Hay dos maneras irreconciliables de entender el sentido de las instituciones políticas, incluido el derecho. Por un lado, hay una manera liberal de entender dichas instituciones según la cual ellas se conciben como instrumentos para purgar vicios privados colectivamente, ya sea a través de la efectiva creación de individuos más virtuosos (p.ej. Hurka) ${ }^{1}$ o a través de la provisión de mecanismos que hacen que los vicios privados trabajen para el beneficio del bien público (como lo hace Rawls). ${ }^{2}$ En marcado contraste con esta concepción existe una concepción de las instituciones políticas como un espacio de mediación entre la necesidad de tomar decisiones concretas en situaciones particulares y el sentido 'trascendente' (a falta de un mejor término), nunca plenamente alcanzable, de esas decisiones.

Las instituciones median entre la 'trascendencia' y la inmanencia en el sentido de que ofrecen mecanismos que ayudan a responder la pregunta acerca de qué debe hacerse en casos concretos, al mismo tiempo que apuntan a un sentido último que se encuentra más allá de ellas mismas. Para el adversario del liberal, las instituciones políticas crean un espacio en el cual la discusión política (no meramente académica) sobre el sentido último de la vida en común -es decir, las preguntas acerca de qué es lo que constituye a la justicia en esa comunidad, cuáles son los deberes recíprocos entre ciudadanos, etcétera.- se hace posible porque se encuentra relativamente aislada de las presiones de decidir qué hacer aquí y ahora. Además, hace posible la acción política porque la aísla parcialmente de la discusión fundamental acerca del sentido de la vida en común. Por tanto, el sentido de la vida en común es la energía que mueve la máquina, la fuerza que lo impregna todo y que hace que el proyecto político tenga sentido, el fundamento de todo argumento político, mientras que, al mismo tiempo, se encuentra relativamente aislada de la práctica institucional y, en ese sentido, se sitúa más allá de ella.

Los liberales niegan que el sentido de lo político se encuentre más allá de las instituciones políticas y creen que la política se resuelve a sí misma dentro

1 Hurka (1996), pp. 147 y ss. Los perfeccionistas liberales pueden reclamar ser herederos de una tradición que se remonta hacia atrás hasta la República de Platón y tiene su locus classicus en la Política de Aristóteles. Aristóteles (1991), 1131b24-1132b12. Sin embargo, los perfeccionistas modernos son víctimas de una confianza en su propia habilidad para construir instituciones apropiadas, confianza de la que Aristóteles, consciente de la naturaleza esencialmente polémica de los conceptos políticos, nunca fue víctima.

2 RAWLS (1971). 
de las instituciones políticas, como un estudio de su propio ingenio (generando virtud a partir del vicio, o bien público a partir del vicio privado, o alguna otra combinación). Los adversarios del liberalismo son antropológicamente pesimistas y creen que ninguna institución será capaz de lograr esa tarea. Para ellos, las instituciones políticas no están cambiando constantemente porque se estén moviendo (o tratando de moverse) hacia una versión más perfecta de sí mismas, sino porque nunca alcanzarán a realizar plenamente aquello que, encontrándose más allá de ellas, las anima.

Carl Schmitt ha ofrecido la mejor descripción de este papel mediador de la forma jurídica. La forma jurídica media entre la decisión concreta en comunidades políticas concretas y el ideal (de verdad, justicia o, como a veces lo pone Schmitt, la idea de derecho). Como escribió en Teología Política:

Los viejos opuestos aristotélicos de deliberación y acción empiezan con dos formas distintas; mientras que es posible aproximarse a la deliberación a través de la forma jurídica, a la acción solo es posible aproximarse a través de una formación técnica. La forma jurídica es gobernada por la idea jurídica y por la necesidad de aplicar un pensamiento jurídico a una situación fáctica, lo que significa que es gobernada por el derecho que auto-evoluciona en el sentido más amplio. Puesto que la idea jurídica no puede realizarse a sí misma, necesita de una organización y forma particular antes de que pueda traducirse en la realidad. ${ }^{3}$

Schmitt jamás dejó de elogiar la intuición de Hobbes de que 'auctoritas non veritas facit legem' ${ }^{4}$ pero eso no quiere decir que la verdad (es decir, la verdad acerca del sentido último de la vida en común) fuese irrelevante en la justificación del derecho. La pretensión de actuar según la verdadera concepción del sentido de la vida en común está presente en todas las facciones de la sociedad que avanzan una agenda política particular y, por consiguiente, la pretensión de verdad no puede por sí misma diferenciar una propuesta política o una regulación jurídica de otra. Como Schmitt sabía muy bien, la pregunta políticamente importante es, por supuesto, quién decide.

Sin embargo, ello no debiera oscurecer el hecho de que la decisión políti$c a$ se presenta a sí misma como una interpretación de la verdad, y no como la imposición de un interés de alguna facción de la sociedad. Esta idea está en el centro de la crítica de Schmitt a la democracia parlamentaria. Los parlamentos solo pueden ser instituciones políticas propiamente tales si es que son verdaderos

3 Schmitt (2005), p. 28.

4 Schmitt (2005), p. 33. 
espacios de deliberación. Cuando se convierten en puestos de negociación, los parlamentos pierden su específica politicidad y quedan sujetos a la némesis de lo político, a saber: pura racionalidad económica. ${ }^{5}$

Es ese compromiso con la verdad acerca del sentido de la vida en común el que es asumido como condición de todo discurso jurídico y político. La autoridad política no se encuentra, por supuesto, condicionada a que la concepción particular del sentido de la vida en común que sostiene el soberano sea verdadera. Pero el hecho de que la autoridad política (entendida como distinta a la de un ladrón poderoso) tenga que presentarse a sí misma como defendiendo una concepción de la vida en común tiene importantes consecuencias. La pretensión de tener autoridad política y el derecho que se relaciona con dicha autoridad siempre apunta hacia algo que no puede ser plenamente realizado en el mundo, hacia una forma de conectividad que se encuentra más allá de ella misma. Desarrollar qué pueda significar esa conexión es una tarea abrumadora y, como se ha explicado más arriba, esta es una de las razones fundamentales por las que se necesitan instituciones.

Así, la pretensión de supremacía política siempre implica que la autoridad afirma tomar en consideración en sus decisiones el interés de la totalidad del grupo político (y no solo de alguna de sus facciones). La razón básica de por qué el interés de todos y cada uno de los miembros del cuerpo político tiene que ser tomado en consideración es el hecho de que la autoridad reconoce una conectividad relevante entre ellos. Esta es la razón por la cual la distinción amigo-enemigo es tan importante. Al establecer la frontera entre amigo y enemigo, la autoridad establece una comunidad entre los miembros de un grupo particular $\mathrm{y}$, al hacerlo, la realización de todos se convierte en un aspecto relevante de la realización de los demás.

Lo que eso significa es que, lo reconozcan o no, todos los miembros de una comunidad política particular tienen un interés en la realización de todos los demás. Desde esta perspectiva, la red social políticamente relevante de cada uno va más allá del grupo de personas que uno quiere e incluso del grupo de personas que uno conoce. Incluye a personas a las que uno nunca ha conocido y a personas a las que uno nunca conocerá. Esta ausencia de cercanía no detrae del hecho de que la realización de todos los miembros de la comunidad relevante está conceptualmente relacionada a la realización de los demás.

5 Schmitt (1988), pp. 4 y ss. Para la tiranía de la racionalidad económica, véase SchmitT (2008), p. 26. 
Nótese el abismo entre esta concepción política de conectividad y una concepción puramente moral de conectividad, como aquella desarrollada por los perfeccionistas liberales. Esta última depende de una teoría sustantiva del interés de todos los miembros de la comunidad y, por esa razón, tiene mayor dificultad en acomodar el carácter esencialmente polémico de los conceptos políticos. Una concepción política de la conectividad, aunque no es de ningún modo vacía, reconoce esta característica de los conceptos políticos y concibe las instituciones políticas como mediadoras entre versiones opuestas de la conexión sustantiva y la decisión común concreta.

En efecto, dentro de esta concepción de la conectividad política hay amplio espacio para el desacuerdo. Puede haber desacuerdo respecto de cuál es o debe ser la comunidad relevante; respecto de si las elecciones autodestructivas hechas por un individuo pueden limitar el impacto de su propio fracaso en realizar su pleno potencial sobre la autorrealización de otro; respecto de cuál sea la división de trabajo social apropiada en relación con lo que puedan necesitar distintas clases de individuos; respecto de si esta ayuda puede ser exigida como un derecho frente a otros, etcétera.

Con todo, el derecho, como institución política, es siempre una expresión de esa conectividad política y, en último término, siempre responde ante ella.

Ciertamente, esto no deja de ser polémico. Esta 'pretensión de conectividad' está en marcada oposición no solo con el individualismo liberal, sino también con toda otra forma de instrumentalismo jurídico puro. Para los instrumentalistas políticos, el derecho es un arreglo social cuya justificación se encuentra en su capacidad para producir ciertos estados de cosas que son evaluados por estándares independientes. La peculiaridad del liberalismo es la de pensar en el derecho como un instrumento para preservar un ámbito privado relevante de la interferencia por parte de otros.

El instrumentalismo puro es una concepción popular del valor del derecho ${ }^{6}$, esté o no asociada con la idea de que el derecho es un instrumento neutro. Uno podría pensar que el derecho, como institución, es de una u otra manera parcial y de todos modos mantener una visión instrumentalista del mismo. Desde una perspectiva instrumentalista, por tanto, podría sostenerse que el derecho solo es el heraldo de la conectividad si alguna de sus características (p.ej., su lenguaje) mostrara una parcialidad hacia el tipo de conectividad descrita más arriba. Este escritor no cree que esto sea cierto y, por cierto, no está solo en creerlo. Por

6 Un resumen instructivo de concepciones instrumentalistas puede encontrarse en TAMANAHA (2006), pp. 118 y ss. 
ejemplo, la afirmación común de que el lenguaje de los derechos individuales, tan omnipresente en los sistemas jurídicos occidentales modernos, privilegia una visión individualista parece ser perfectamente razonable. El argumento aquí defendido de que el derecho siempre reclama una pretensión de conectividad es compatible tanto con la tesis de la tendencia individualista de ciertas características centrales del derecho contemporáneo como con la tesis de que ciertas facciones sociales suelen utilizar el derecho para servir sus propios intereses.

La visión instrumentalista del derecho tiene razón, por cierto, al decir que el derecho es un instrumento apropiado (a veces el mejor o incluso el único) para alcanzar ciertos objetivos. Pero cualquier pretensión de que el derecho debe ser respetado sin perjuicio de su valor instrumental debe suponer que, en un nivel profundo, el derecho es una expresión de la conexión intrínseca entre la realización de cada miembro de la comunidad relevante. Esto es lo que Tomás de Aquino parece querer decir cuando afirma que la ley está intrínsecamente relacionada con el bien común (entendido como opuesto al bien de una facción dentro del grupo social). ${ }^{7}$

Ahora bien, es un hecho innegable que facciones de sociedades particulares con frecuencia utilizan la ley en orden a favorecer sus propios intereses en detrimento del bien común. En efecto, la relación entre derecho y conectividad no quiere decir que el derecho siempre será un medio eficiente para crear comunidad. Lo que quiere decir es simplemente que existe una disonancia filosófica significativa en el hecho de utilizar el derecho para destruir políticas públicas que encarnan esa conexión.

Esta disonancia surge del hecho de que, cuando el derecho es utilizado por alguien que no cree en esa conectividad esencial de personas en una comunidad política para tratar de dar una nueva forma a la sociedad según los dictámenes de una concepción individualista del mundo político, esto se hace en nombre del interés que tiene la facción del gobernante en el bienestar de todos los miembros de la comunidad política. Al tratar de dar forma a las instituciones para reflejar el supuesto desinterés de las personas en su realización recíproca, la facción gobernante debe tener la pretensión de estar interesada en la realización de todos los miembros del grupo social.

De este modo, decir que el derecho es una expresión de conectividad social o que el derecho está intrínsecamente relacionado con el bien común no es ni suscribir a una visión optimista de cómo opera el derecho en el mundo, ni pre-

7 Tomás de Aquino (1966), 1a2ae, cuestión 90, art. 2. 
tender que si el derecho no está orientado al bien común entonces no es derecho (la caricatura del derecho natural que fue el hombre de paja para una generación de filósofos del derecho).

Este no es un argumento completo para defender la tesis de que las instituciones políticas (paradigmáticamente, las instituciones jurídicas), deben siempre pretender que existe una conectividad esencial entre los miembros de una comunidad política particular, sino más bien el bosquejo de cómo se vería ese argumento. En lo que sigue, este análisis será bastante generoso con el argumento tal y como aquí ha sido desarrollado y asumirá la verdad de su conclusión. Si esto es así, surge la pregunta de cómo (y si) puede concebirse lo privado como un espacio políticamente relevante, es decir, en términos de incorporar la noción de conectividad que es una condición conceptualmente necesaria para lo político.

\section{EL ENIGMA DE LA CONECTIVIDAD PRIVADA}

Para entender cómo lo privado se posiciona a sí mismo en el contexto del argumento es necesario aclarar y demarcar más precisamente qué se entiende por lo privado. Esto es particularmente importante dado que, como justamente ha advertido Raymond Geuss, existe la posibilidad de que haya demasiados conceptos bajo la misma etiqueta de 'privado' que haríamos bien en tratar separadamente. Como él lo explica:

$[\mathrm{N}]$ o hay una sola distinción entre público y privado; los diversos sentidos de 'público' no tienen demasiada relación unos con otros, así como tampoco la tienen los sentidos de 'privado'; las diversas formas de oposición entre 'público' y 'privado' no son ni absolutas ni son todas ellas, al final, insustanciales e ilusorias. ${ }^{8}$

Aunque la advertencia de Geuss sobre los peligros de ser excesivamente incluyentes cuando tratamos del concepto de 'privado' es fundamentalmente correcta, es importante notar que parece haber ciertas características estructurales comunes de los argumentos acerca de la división público/privado. Postular una distinción entre lo público y lo privado es usualmente el primer paso en un argumento contra un desbordamiento entre los dos ámbitos. Esta idea está presente en muchas de las formas de distinguir entre lo público y lo privado identificadas por Geuss. La idea de aislamiento está presente (a) en la concepción de 'público' como la esfera la de no-intromisión, es decir, que ciertas acciones son apropiadas en el ámbito privado, pero no debieran desbordarse hacia el dominio

8 Geuss (2001), p. 109. 
público porque serían obstructivas en relación con otros ${ }^{9}$ así como también en (b) la reconstrucción de lo público como un espacio donde solo deben prevalecer razones acerca del bien común, en oposición a razones de bien privado ${ }^{10} \mathrm{y}$ es, por supuesto, (c) la mayor preocupación de la teoría liberal de lo privado, la cual será el centro del análisis que sigue más abajo.

La teoría liberal de lo privado no es simplemente un intento de construir una barrera de aislamiento entre la esfera privada y la esfera pública. También especifica otro sentido, más particular, en el que la distinción público/privado puede considerarse una distinción relativa al aislamiento. Para los liberales, lo privado es un ámbito de no-conectividad, de aislamiento, en contraste con lo público como un ámbito fundado en la conectividad. Si la distinción público/privado se formula de esta manera, la separación entre ambos ámbitos es una separación entre un ámbito en el que la realización de una persona está intrínsecamente conectada a la realización de otros, en el que la tragedia de otro es también la tragedia de esa persona, y un ámbito en el que el destino de los otros no es necesariamente relevante para esa persona (aunque uno pueda elegir hacerlo relevante).

Si la distinción se entiende de esta manera, podría parecer que la discusión no es tanto sobre dos esferas de acción diferentes, sino sobre dos perspectivas éticas rivales que no pueden reconciliarse fácilmente en una sola posición política. Podría parecer que el destino de otros o es relevante para una persona o no lo es. Una manera de tratar de soslayar dicha objeción es concebir la autorrealización como una actividad compleja. Podría decirse que ciertos aspectos de la realización de una persona no están condicionados por la autorrealización de otros, mientras que otros no se pueden alcanzar si es que otros tampoco los alcanzan. Tomado aisladamente, tener suficiente alimento es ciertamente un aspecto de la realización personal que tiene solo una conexión contingente con que otros se autorrealicen (porque tienen suficiente alimento ellos mismos, porque tienen educación apropiada o cualquier otro aspecto de su autorrealización). Por otro lado, puede ser que la autorrealización de una persona sea también dependiente de un proyecto común que no puede ser plenamente realizado de forma individual por cualquiera, pero que, de ser exitoso, enriquecería la vida de todos. Esa es la manera en la que Arendt pensó lo público como un ámbito de igualdad (necesariamente dependiente de otros), trabajo, obras y discurso. ${ }^{11}$ Discurso y acción dependen de la existencia de una comunidad de iguales, todos libres de la nece-

9 Geuss (2001), pp. 12 y ss.

10 Geuss (2001), pp. 34 y ss.

11 Arendt (2005), pp. 122 y ss., Arendt (1998), pp. 50-58. 
sidad, algo que no se encuentra, ella cree, en el ámbito privado. ${ }^{12}$ Por supuesto, lo que falta en este argumento es una justificación para tomar esos aspectos de la autorrealización aislados unos de otros, pero este artículo no necesita entrar en el detalle del argumento de Arendt. ${ }^{13}$

Más importante en el contexto de este artículo es discutir la concepción liberal de lo privado, puesto que es el liberalismo el que pone el ámbito privado en oposición a la tesis de la conectividad. El liberalismo concibe el ámbito privado como el dominio en el que la posición por defecto es que otros no pueden imponer exigencias en una persona. Es un espacio en el que toda conexión significativa que pueda darse entre individuos es elegida libremente; en el que la realización de otros es únicamente importante para alguien si es que él o ella eligen que así sea. En esta concepción, la esfera privada está poblada por un individuo en un mar de objetos, donde el otro no se concibe con un estatus distinto, sino como un obstáculo más en la persecución de los objetivos personales libremente elegidos. El otro se presenta ante una persona de una manera que no es esencialmente diferente de la que se presenta un tigre o una piedra.

Lo importante aquí es percibir que esta objetivación del otro no es tanto una característica psicológica de los seres humanos (o incluso de los hombres occidentales modernos), sino más bien un presupuesto conceptual de una concepción liberal del mundo político.

Una concepción de la política como mediación no tiene que ser antropológicamente optimista para ver una salida a esta objetivación del otro. Las instituciones políticas no son primariamente un medio para hacernos mejores personas, quienes percibiríamos la relevancia del otro y la importancia de la realización de los otros para nuestra propia realización (como un perfeccionista estaría tentado de creer). Tampoco son las instituciones ingeniosos mecanismos que hacen trabajar al vicio privado en beneficio de un criterio de justicia definido independientemente, como en la justicia procedimental de Rawls.

12 Arendt (1998), pp. 70-72.

13 Arendt trata de justificar la separación refiriéndola a su concepción de la libertad. A juicio de Arendt, la vida práctica se desarrolla en dos frentes mutuamente dependientes. En el frente privado, los agentes son movidos por el impulso de asegurarse frente a las fuerzas de la necesidad, buscando satisfacer las necesidades básicas del mero vivir. Liberarse de la necesidad es una condición para la libertad política. La posibilidad de un frente público depende de la presencia de las condiciones que le dan sentido a la vida privada: lo público es el espacio ocupado por aquellos que están libres de la necesidad. Lo que parece faltar es una explicación de por qué la satisfacción de la necesidad en la comunidad no debiera ser una tarea política valiosa. 
Las instituciones políticas (y el derecho en particular) proporcionan una salida de la objetivación al encarnar ellas mismas una cierta concepción de la conectividad. Esa idea parece ofrecer la clave para entender el derecho privado de una manera no puramente instrumental.

\section{EL DERECHO PRIVADO EN LA ESFERA PRIVADA}

Esta sección reúne los dos hilos argumentativos presentados en las secciones precedentes. Por un lado, está la concepción de las instituciones políticas, incluyendo el derecho, como instituciones que encarnan una pretensión de conectividad, y, por el otro, una breve crítica de la concepción liberal de lo privado como ámbito de 'emancipación' del otro, de libertad de elegir como a uno le plazca, sin tomar en consideración a los demás. La pregunta que será examinada ahora es cómo (y si) el ámbito privado puede considerarse un espacio de conexión significativa, algo más que un mundo solipsístico de objetivación del otro.

He aquí la tesis del artículo en pocas palabras: la clave para entender el ámbito privado como un espacio de conexión significativa es el derecho privado. El derecho privado otorga sentido conectivo a las interacciones de los agentes privados en la esfera privada al mismo tiempo que mantiene el sentido en el cual la esfera privada es una esfera de conexión elegida libremente. Allí reside la naturaleza pública del derecho privado y esta naturaleza, a su vez, determina (o debiese determinar) sus características principales.

El pesimismo antropológico en la raíz de la concepción de la política desarrollada más arriba en la primera sección implica que la motivación por defecto de los agentes en la esfera reservada para su elección libre es la de maximizar la utilidad. Los agentes, dejados en libertad para decir qué hacer, elegirán un curso de acción que maximiza su utilidad en detrimento de todos los demás. Ahora bien, esto no debe tomarse como una afirmación sociológica acerca de cómo se comportan de hecho las personas. Como MacNeil apuntó, ${ }^{14}$ las personas envueltas en relaciones contractuales muchas veces se comportan de manera relativamente compasiva como potenciadores de utilidad (quienes solo contratan porque desean obtener algún beneficio, pero están también dispuestos a ganar menos de lo que podrían para ayudar a otros). Algunas personas incluso actúan compasivamente sin tener a la vista alguna ganancia personal. De hecho, un maximizador de utilidad impecable, que no vea valor en que otros obtengan ganancia sería, clínicamente, un psicópata.

14 MacNeIL (1986), pp. 577 y ss. 
Esto puede ser sociológica o psicológicamente cierto, pero Hobbes, Aristóteles y otros pesimistas antropológicos no están simplemente haciendo una afirmación sociológica acerca de cómo se comportan las personas. Están haciendo una afirmación conceptual acerca del hecho de que, en ausencia de un marco institucional que haga que ciertos tipos de acciones tengan incorporada por necesidad una preocupación por el otro, que alguien envuelto en una transacción discreta (p.ej. un contrato particular) no tenga en cuenta los intereses de las demás partes en la transacción sería algo que no llamaría en absoluto la atención. Lo que genera este marco institucional son las condiciones para la política, en el sentido de que la institución siempre actúa a nombre de todos sus miembros en conjunto (como fue explicado en la primera sección).

Dori Kimel plantea algo similar cuando argumenta en contra de concebir a los contratos como promesas. ${ }^{15}$ Las promesas suponen un contexto de entendimiento y confianza entre promitente y promisario, mientras que los contratos se necesitan en aquellos contextos en los que uno no puede confiar en que el otro se comportará de una determinada manera.

Este es el rol público del derecho privado, infundir el espacio privado, donde no se puede confiar en que los agentes tomarán en consideración las necesidades e intereses del otro, con la idea de respeto mutuo. Lo que hace el derecho privado, principalmente, es hacer obligatorias ciertas formas de comportamiento que manifiestan ese respeto. El derecho privado tiene otras funciones que están solo indirectamente relacionadas con este rol central, por ejemplo, la de crear condiciones en las que sea más fácilmente comprobable que un determinado comportamiento manifiesta respeto hacia el otro (p.ej., introduciendo reglas para determinar qué cuenta como una promesa válida, cuál sea por defecto el tiempo y plazo del pago, etcétera). Más aun, qué constituye precisamente respeto por el otro es tan controversial como cualquier concepción sustantiva de la justicia y la comunidad debiera zanjarlo tal y como zanja la mayoría de las materias de justicia: mediante la política.

Lo que hace el derecho privado en el ámbito privado es convertirlo en un espacio para una conexión significativa entre partes privadas. Lo verdadero de la concepción liberal del espacio privado es que el espacio privado no contiene en sí mismo un antídoto para la objetivación del otro. Y el hecho de que esa objetivación es una posibilidad conceptual en todo el espacio privado, así como también un hecho social común en muchas transacciones discretas, harían del ámbito privado un ámbito en el que la conexión significativa con el otro fuera puramente contingente. Lo que el derecho privado hace es hacer presente al

15 Kimel (2003), pp. 60, 65, 72 y ss. 
otro, a pesar de la reticencia en ver al otro como algo más que un objeto que obstaculiza la satisfacción de nuestros propios deseos.

Esto no significa que el derecho privado nos haga ver a la otra persona y responder apropiadamente ante ella. Esto puede o no ocurrir y, si lo hace, sería un bienvenido resultado derivado del derecho privado. Lo que es más importante es que el derecho privado hace que nuestro comportamiento sea compatible con ser respetuoso (incluso si uno solo ve el derecho como otra piedra más bloqueando el camino de la propia satisfacción). El marco psicológico de una persona puede o no volverse político (es decir, preocupado por el otro), pero la acción conforme a derecho de esa persona necesariamente imitará la acción de alguien cuyo comportamiento muestra una preocupación por el otro. Ese es el sentido en el que el derecho privado infunde al ámbito privado con publicidad.

Es de esperar que esto pueda iluminar cómo construir una narrativa adecuada del desarrollo del derecho privado, en particular desde el comienzo del Siglo Veinte. El surgimiento del derecho del trabajo y del derecho del consumidor, la relevancia creciente de la buena fe, el crecimiento de la responsabilidad por producto defectuoso y de la coerción económica en el derecho de contratos, junto a muchos otros aspectos de la evolución del derecho privado, no debieran ser considerados como intrusiones necesarias en un sistema que conserva su independencia normativa y conceptual respecto de esas intromisiones aceptadas a regañadientes. En vez de ello, la narrativa del desarrollo del derecho privado es una narrativa en la que las personas (colectivamente, si no individualmente) progresivamente perciben maneras más sofisticadas de entender lo que significa manifestar respeto, una sofisticación que a veces es motivada por cambios en las condiciones sociales de trasfondo y en ocasiones es simplemente resultado de una profundización en el entendimiento acerca de cómo mostrar respeto por el otro. En este sentido, la buena fe y el derecho laboral son aspectos de la plena realización del derecho privado en el mundo tanto como lo es la idea de que uno debe cumplir con sus promesas. El desafío crítico que tienen por delante los iusprivatistas y la comunidad política en general es reconocer los próximos pasos en esta narrativa de realización de una institución cuyo objetivo es infundir el ámbito privado con conectividad. Este no es solo el desafío por delante para esta generación, sino que el horizonte hacia el cual se mueven los iusprivatistas.

Decir que la narrativa del derecho privado debe ser entendida como un proceso de profundización en el entendimiento de la conexión política entre partes privadas, en vez de la narrativa de una estructura conceptual central que, desarrollándose desde una idea de libertad individual, está preparándose constantemente para la batalla y siendo traspasada por la necesidad de lidiar con necesidades sociales (protección al consumidor, etcétera), no es la historia completa. Esa na- 
rrativa reconstruida simplemente abre un espectro de otras preguntas acerca de cómo el respeto en la esfera privada difiere del respeto en la esfera pública, sobre el contenido de esta forma de respeto y sobre la relación entre las instituciones concretas del derecho privado y aquella noción de 'respeto' privado, ninguna de las cuales puede examinarse aquí. 


\section{BIBLIOGRAFÍA CITADA}

Arendt, Hannah (1998): The Human Condition (University of Chicago Press, $2^{\text {da }}$ ed.).

Arendt, Hannah (2005): The Promise of Politics (Schocken Book).

Aristóteles (1991): "Política", en Barnes, Jonathan (ed.), The Complete Works of Aristotle, Vol. 2 (trad. Benjamin Jowett, Princeton University Press).

Geuss, Raymond (2001): Public Goods, Private Goods (Princeton University Press).

Hurka, Thomas (1996): Perfectionism (Oxford University Press).

Kimel, Dori (2003): From Promise to Contract (Hart Publishing).

MacNeIL, Ian (1986): "Exchange Revisited: Individual Utility and Social Solidarity", Ethics, Vol. 96, N 3, pp. 567-593.

RAwLS, John (1971): A Theory of Justice (Harvard University Press).

Schmitt, Carl (1988): The Crisis of Parlamentary Democracy (trad. Elen Kennedy, MIT Press).

Schmitт, Carl (2005): Political Theology (trad. George Schwab, University of Chicago Press).

Schmitt, Carl (2008): La Tirannia dei Valori (trad. Sara Bignotti y Paolo Becchi, Morcelliana).

Tamanaha, Brian (2006): Law as a Means to an End (Cambridge University Press).

Tomás de Aquino (1966): Summa Theologiae, Vol. 28 (trad. Thomas Gilby, Blackfriars). 
